\title{
Assessment of Minimum Inhibitory Concentrations of Telavancin by Revised Broth Microdilution Method in Phase 3 Hospital-Acquired Pneumonia/Ventilator- Associated Pneumonia Clinical Isolates
}

Jennifer I. Smart · Gordon Ralph Corey · Martin E. Stryjewski •

Whedy Wang $\cdot$ Steven L. Barriere

Received: July 28, 2016/Published online: October 7, 2016

(C) The Author(s) 2016. This article is published with open access at Springerlink.com

\section{ABSTRACT}

Introduction: The broth microdilution method (BMD) for testing telavancin minimum inhibitory concentrations (MICs) was revised (rBMD) in 2014 to improve the accuracy, precision, and reproducibility of the testing method. The aim of this study was to determine the effect of the revised method on telavancin MIC values for Staphylococcus aureus (S. aureus) clinical isolates obtained from hospital-acquired pneumonia (HAP) patients.

Methods: Isolates from patients who participated in the phase 3 Assessment of

Enhanced content To view enhanced content for this article go to http://www.medengine.com/Redeem/ 03E6F06001883855.

J. I. Smart $(\bowtie) \cdot$ W. Wang · S. L. Barriere

Theravance Biopharma US, Inc., South San

Francisco, CA, USA

e-mail: jsmart@smartmicrobiology.com

G. R. Corey

Duke University, Durham, NC, USA

M. E. Stryjewski

Department of Internal Medicine and Division of

Infectious Diseases, CEMIC, Buenos Aires, Argentina
Telavancin for Treatment of HAP Studies were retested using the rBMD method.

Results: Retesting of 647 isolates produced a range of telavancin MIC values from $0.015 \mu \mathrm{g} /$ $\mathrm{mL}$ to $0.12 \mu \mathrm{g} / \mathrm{mL}$ with $\mathrm{MIC}_{50 / 90}$ values of $0.06 /$ $0.06 \mu \mathrm{g} / \mathrm{mL}$ for the total pool of samples. For methicillin-resistant $S$. aureus (MRSA), $\mathrm{MIC}_{50 / 90}$ values were $0.06 / 0.12 \mu \mathrm{g} / \mathrm{mL}$. These values are up to 4-fold lower than $\mathrm{MIC}_{50 / 90}$ values obtained using the original method. These results were used in part to justify lowering the telavancin breakpoints. All tested isolates remained susceptible to telavancin at the revised susceptibility breakpoint of $\leq 0.12 \mu \mathrm{g} /$ $\mathrm{mL}$. Overall, the clinical cure rate for microbiologically evaluable telavancin-treated patients was $78 \%$ for $S$. aureus, $76 \%$ for patients with MRSA, and $79 \%$ for patients with isolates with reduced susceptibility to vancomycin (MIC $\geq 1 \mu \mathrm{g} / \mathrm{mL}$ ).

Conclusion: Results from the rBMD method support the in vitro potency of telavancin against $S$. aureus.

Trial registration: ATTAIN (NCT00107952 and NCT00124020).

Funding: Theravance Biopharma Antibiotics, Inc. 
Keywords: Hospital-acquired pneumonia; Lipoglycopeptide; Staphylococcus aureus; Telavancin; Ventilator-associated pneumonia

\section{INTRODUCTION}

Staphylococcus aureus (S. aureus) infections are a major cause of pneumonia and are especially implicated in hospital-acquired pneumonia (HAP), ventilator-associated pneumonia (VAP), and healthcare-associated pneumonia [1]. The recent Infectious Diseases Society of America guidelines recommend treating HAP/VAP patients with either vancomycin or linezolid [2]. Higher vancomycin minimum inhibitory concentrations (MICs) have been associated with more frequent treatment failure and higher mortality rates [3-6]. Telavancin (Theravance Biopharma Antibiotics, Inc., George Town, Grand Cayman, Cayman Islands) is a parenteral bactericidal lipoglycopeptide antibiotic that has a dual mechanism of action [7-10]. Telavancin is approved in the US, Canada, Russia, and Europe for treatment of HAP, including VAP that is caused by susceptible isolates of $S$. aureus (methicillin-resistant $S$. aureus [MRSA] only in Europe). In the US, Russia, and Europe, the indication is limited to infections in which alternative medicines are unsuitable $[8,11,12]$. In the Assessment of Telavancin for Treatment of Hospital-Acquired Pneumonia [ATTAIN (ClinicalTrials.gov identifiers NCT00107952 and NCT00124020)] studies, a total of 1503 patients with HAP were treated with telavancin or vancomycin for up to 21 days. Telavancin demonstrated noninferiority to vancomycin, achieving similar cure rates [13].

Drug loss due to binding to plastics in the MIC assay has been found with other lipoglycopeptides and is resolved with the addition of polysorbate 80 (P-80) [14, 15]. To improve the accuracy and precision of telavancin susceptibility testing, a revised broth microdilution method (rBMD) MIC testing method for telavancin was approved by the US Food and Drug Administration (FDA) and published by Clinical and Laboratory Standards Institute (CLSI) in 2014 to include dimethyl sulfoxide (DMSO) in the diluent to improve solubility and P-80 in the broth microdilution assay cation-adjusted Mueller-Hinton broth (CAMHB) to reduce drug loss due to binding to plastic $[8,16,17]$. This revised method has produced up to 8 -fold lower telavancin MIC results compared with the previous method [17] and has been used to establish new values for telavancin activity against a variety of clinical isolates [18, 19]. The FDA and CLSI previously have approved $\leq 0.12 \mu \mathrm{g}$ / $\mathrm{mL}$ as the telavancin MIC susceptibility breakpoint for $S$. aureus [both methicillin-susceptible $S$. aureus (MSSA) and MRSA] isolates; intermediate or resistant breakpoints for telavancin have not been established as of 2016, due to the rarity of telavancin-resistant $S$. aureus isolates $[8,20]$. The objective of this study was to determine the effect of the revised method on telavancin MIC values for $S$. aureus clinical isolates obtained from the ATTAIN HAP/VAP patients and evaluate the clinical outcome by the revised telavancin MICs. These results were part of the data package presented to breakpoint setting committees, including FDA, CLSI, and the European Committee on Antimicrobial Susceptibility Testing for the evaluation of the revised telavancin breakpoints. 


\section{METHODS}

\section{Patient Population and Study Procedures}

The protocol for the ATTAIN studies has been presented elsewhere [13]. Briefly, these were identical, randomized, double-blind, comparator-controlled phase 3 trials (ClinicalTrials.gov identifiers NCT00107952 and NCT00124020) in which inpatients who developed pneumonia caused by Gram-positive infections were randomized to receive telavancin $(10 \mathrm{mg} / \mathrm{kg}$ every $24 \mathrm{~h})$ or vancomycin ( $1 \mathrm{~g}$ every $12 \mathrm{~h}$ ) for 7 to 21 days [13]. The primary endpoint of the study was the investigator-assessed clinical response at a follow-up/test-of-cure visit between 7 and 14 days after the last dose of study medication. Respiratory and blood culture specimens were collected at baseline, and isolates underwent susceptibility testing and confirmation at a central laboratory (Covance Laboratories, Indianapolis, IN, USA; Duke Clinical Research Institute, Durham, NC, USA).

Clinical cure rates by MIC reported in the ATTAIN trials were reassessed using the MICs obtained using the rBMD method. In the ATTAIN studies, the clinically evaluable study population consisted of patients who met study inclusion criteria and adhered to study protocol such that their clinical outcome could be considered to accurately reflect the effects of study medication. The microbiologically evaluable population in the ATTAIN studies included all clinically evaluable patients who had a Gram-positive (S. aureus in this analysis) respiratory pathogen at baseline. Presumed microbiological eradication was defined as failing to identify the baseline pathogen in the last postbaseline culture or if the patient was clinically cured and there were no follow-up cultures available.
rBMD

The analysis of the effects of telavancin on clinical isolates from the ATTAIN studies was performed using the rBMD method at JMI Laboratories (North Liberty, IA, USA). Telavancin stock solutions of $1600 \mu \mathrm{g} / \mathrm{mL}$ were prepared by dissolving dry powder in DMSO in a glass vial; stock solutions were further diluted in DMSO to achieve intermediate concentrations ranging from 0.004 to $8 \mu \mathrm{g} / \mathrm{mL}$, per CLSI recommendations [16]. The telavancin/DMSO solutions were further diluted $100 \times$ in CAMHB containing $0.002 \%$ (volume/volume) P-80 (Tween 80; Croda International, Snaith, UK) to minimize adhesion to plastic surfaces. Following dilution, $100-\mu \mathrm{L}$ aliquots of telavancin solutions ranging in concentration from 0.004 to $8 \mu \mathrm{g} / \mathrm{mL}$ were dispensed into 96 -well plates. Comparator agents tested against the same $S$. aureus isolates included linezolid (MIC range $0.25-4 \mu \mathrm{g} / \mathrm{mL}$ ), ampicillin (MIC range $0.25-32 \mu \mathrm{g} / \mathrm{mL}$ ), and vancomycin (MIC range $0.25-16 \mu \mathrm{g} / \mathrm{mL})$.

\section{Clinical Isolates}

Isolates were sent from the ATTAIN study central laboratories (Covance Laboratories) to JMI Laboratories for retesting using the rBMD method. The isolates were stored at $-80{ }^{\circ} \mathrm{C}$ at Covance, then were shipped to JMI laboratories on dry ice, where they were stored at $-80^{\circ} \mathrm{C}$. Minimum inhibitory concentration values were assessed for $S$. aureus isolates from the ATTAIN studies. Sample quality was assured via concurrent testing of CLSI-recommended quality control (QC) reference strains (S. aureus American Type Culture Collection [ATCC ${ }^{\circledR}$ ] 29213, Enterococcus faecalis ATCC 29212, and S. pneumoniae ATCC 49619, Manassas, VA, 
USA). All QC MIC results for control strains were within acceptable ranges defined by CLSI [16].

\section{Statistical Analyses}

All the analyses were descriptive and performed using SAS ${ }^{\circledR} 9.4$ software (Cary, NC, USA).

\section{Compliance with Ethics Guidelines}

This article is based on previously conducted studies, and does not involve any new studies of human or animal subjects performed by any of the authors.

\section{RESULTS}

A total of $647 \mathrm{~S}$. aureus isolates from patients with HAP in the ATTAIN studies were analyzed for telavancin MICs using the rBMD method (644 samples were tested using the original method). Three isolates that did not have an initial central laboratory MIC result and were not included in the original susceptibility analysis were included in this set of retested isolates. Overall, 240 isolates were MSSA isolates, and 407 were MRSA isolates.

The MIC values obtained using the rBMD method for telavancin and control agents tested against ATTAIN $S$. aureus isolates were within the CLSI-approved and accepted QC ranges determined using S. aureus ATCC 29213 (telavancin $\quad 0.03-0.12 \mu \mathrm{g} / \mathrm{mL}, \quad$ ampicillin $0.5-2.0 \mu \mathrm{g} / \mathrm{mL}$, linezolid $\quad 1.0-4.0 \mu \mathrm{g} / \mathrm{mL}$, vancomycin $0.5-2.0 \mu \mathrm{g} / \mathrm{mL}$ ) [16].

Telavancin MICs for all $S$. aureus isolates ranged from 0.015 to $0.12 \mu \mathrm{g} / \mathrm{mL}$, with a range of 0.015 to $0.12 \mu \mathrm{g} / \mathrm{mL}$ for MSSA isolates and 0.015 to $0.12 \mu \mathrm{g} / \mathrm{mL}$ for MRSA isolates (Table 1 ). For the overall set of $S$. aureus isolates and for
MSSA isolates, telavancin $\mathrm{MIC}_{50 / 90}$ values were $0.06 / 0.06 \mu \mathrm{g} / \mathrm{mL}$; for MRSA, the telavancin $\mathrm{MIC}_{50 / 90}$ values were $0.06 / 0.12 \mu \mathrm{g} / \mathrm{mL}$. These results represent a substantial downward shift in telavancin MIC values for S. aureus compared with the MICs obtained using the original method (Fig. 1), which produced higher values of MICs for telavancin $\left(\mathrm{MIC}_{50 / 90}\right.$ of 0.25 / $0.50 \mu \mathrm{g} / \mathrm{mL}$ for the total pool of $S$. aureus isolates).

Among the 528 isolates with reduced susceptibility to vancomycin (MIC $\geq 1 \mu \mathrm{g} / \mathrm{mL}$ ), telavancin $\mathrm{MIC}_{50 / 90}$ values obtained using the rBMD method were $0.06 / 0.12 \mu \mathrm{g} / \mathrm{mL}$. Among these samples, 166 were MSSA and 362 were MRSA, with $\mathrm{MIC}_{50 / 90}$ values of $0.06 / 0.06 \mu \mathrm{g} / \mathrm{mL}$ for MSSA and $0.06 / 0.12 \mu \mathrm{g} / \mathrm{mL}$ for MRSA, respectively (Table 1 ). These values were lower than the telavancin $\mathrm{MIC}_{50 / 90}$ values for isolates with reduced vancomycin susceptibility generated by the original method, which were $0.25 / 0.5 \mu \mathrm{g} / \mathrm{mL}$ and $0.5 / 0.5 \mu \mathrm{g} / \mathrm{mL}$ for MSSA and MRSA, respectively. The isolates with reduced susceptibility to vancomycin remained susceptible to telavancin (rBMD $\mathrm{MIC}_{50 / 90}$ ) when using the revised FDA-approved breakpoint of $<0.12 \mu \mathrm{g} / \mathrm{mL}$ [8].

A total of 183 isolates exhibited a \pm 1 dilution change in the vancomycin MIC $\geq 1 \mu \mathrm{g} / \mathrm{mL}$ upon retesting. Of those, 1 increased from 0.25 to $0.5 \mu \mathrm{g} / \mathrm{mL}, 110$ increased from 0.5 to $\geq 1 \mu \mathrm{g} / \mathrm{mL}$, 11 increased from 1 to $2 \mu \mathrm{g} / \mathrm{mL}, 50$ decreased from 1 to $0.5 \mu \mathrm{g} / \mathrm{mL}$, and 11 decreased from 2 to $1 \mu \mathrm{g} / \mathrm{mL}$. A total of 2 isolates exhibited a 2-dilution change in the vancomycin MIC upon retesting with 1 increasing from 0.5 to $2.0 \mu \mathrm{g} / \mathrm{mL}$ and 1 decreasing from 2.0 to $0.5 \mu \mathrm{g} /$ $\mathrm{mL}$. These changes can be attributed to random testing differences between two laboratories (Table 1).

The clinical cure rate by revised MIC was assessed in the microbiologically evaluable 
Table 1 Distribution of telavancin MIC values obtained using rBMD on HAP isolates from ATTAIN trials

\begin{tabular}{|c|c|c|c|c|c|c|c|c|c|c|c|}
\hline \multirow[t]{2}{*}{ Organism } & \multirow[t]{2}{*}{ Method } & \multicolumn{10}{|c|}{$\operatorname{MIC}(\mu \mathrm{g} / \mathrm{mL})$} \\
\hline & & $N$ & 0.015 & 0.03 & 0.06 & 0.12 & 0.25 & 0.5 & 1.0 & $\begin{array}{l}\text { Range } \\
(\mu \mathrm{g} / \mathrm{mL})\end{array}$ & $\begin{array}{l}\mathrm{MIC}_{50 / 90} \\
(\mu \mathrm{g} / \mathrm{mL})\end{array}$ \\
\hline \multirow[t]{2}{*}{ S. aureus (all) } & Revised & 647 & 3 & 167 & 413 & $64^{\mathrm{a}}$ & - & - & - & $0.015-0.12$ & $0.06 / 0.06$ \\
\hline & Original & 644 & - & - & 2 & 13 & 346 & 258 & 25 & $0.06-1$ & $0.25 / 0.50$ \\
\hline \multirow[t]{2}{*}{ MSSA } & Revised & 240 & 1 & 94 & 144 & 1 & - & - & - & $0.015-0.12$ & $0.06 / 0.06$ \\
\hline & Original & 239 & - & - & - & 10 & 178 & 50 & 1 & $0.12-1$ & $0.25 / 0.5$ \\
\hline \multirow[t]{2}{*}{ MRSA } & Revised & 407 & 2 & 73 & 269 & 63 & & - & - & $0.015-0.12$ & $0.06 / 0.12$ \\
\hline & Original & 405 & - & - & 2 & 3 & 168 & 208 & 24 & $0.06-1$ & $0.5 / 0.5$ \\
\hline \multirow{2}{*}{$\begin{array}{l}\text { S. aureus vancomycin MIC } \\
\quad \geq 1 \mu \mathrm{g} / \mathrm{mL}\end{array}$} & Revised & 528 & - & 94 & 370 & 61 & $3^{a}$ & - & - & $0.03-0.25$ & $0.06 / 0.12$ \\
\hline & Original & 466 & - & - & - & 7 & 229 & 209 & 21 & $0.12-1$ & $0.25 / 0.5$ \\
\hline \multirow{2}{*}{$\begin{array}{l}\text { MSSA vancomycin MIC } \\
\quad \geq 1 \mu \mathrm{g} / \mathrm{mL}\end{array}$} & Revised & 166 & - & 48 & 117 & 1 & - & - & - & $0.03-0.12$ & $0.06 / 0.06$ \\
\hline & Original & 137 & - & - & - & 5 & 103 & 29 & - & $0.12-0.5$ & $0.25 / 0.5$ \\
\hline \multirow{2}{*}{$\begin{array}{l}\text { MRSA vancomycin MIC } \\
\quad \geq 1 \mu \mathrm{g} / \mathrm{mL}\end{array}$} & Revised & 362 & - & 46 & 253 & 60 & 3 & - & - & $0.03-0.25$ & $0.06 / 0.12$ \\
\hline & Original & 329 & - & - & - & 2 & 126 & 180 & 21 & $0.12-1$ & $0.5 / 0.5$ \\
\hline
\end{tabular}

Data presented as number of isolates except where indicated

ATTAIN Assessment of Telavancin for Treatment of Hospital-Acquired Pneumonia; HAP hospital-acquired pneumonia; MIC minimum inhibitory concentration; MRSA methicillin-resistant $S$. aureus; MSSA methicillin-susceptible $S$. aureus; rBMD revised broth microdilution; S. aureus Staphylococcus aureus

population of telavancin-treated patients (195 patients). The overall telavancin clinical cure rate for $S$. aureus was $78 \%(153 / 195$ patients), with clinical cure rates of $83 \%$ (62/75 patients) and $76 \%$ (91/120 patients) for MSSA- and MRSA-infected patients, respectively (Table 2). The clinical cure rate did not decrease with increasing telavancin MIC values for $S$. aureus obtained using the rBMD method, which ranged from 0.03 to $0.12 \mu \mathrm{g} / \mathrm{mL}$, as clinical cure rates remained $\geq 81 \%$ and $\geq 70 \%$ for MSSAand MRSA-infected patients, respectively, for all MIC values (Table 2). Among the 166 microbiologically evaluable telavancin-treated patients with $S$. aureus isolates that demonstrated reduced susceptibility to vancomycin (MIC $\geq 1 \mu \mathrm{g} / \mathrm{mL}$ ), the clinical cure rate was $79 \%$ (131/166 patients) for telavancin.
The microbiological eradication rates for the overall S. aureus, individual MSSA and MRSA isolates, and isolates with reduced vancomycin susceptibility (MICs $\geq 1 \mu \mathrm{g} / \mathrm{mL}$ ) were comparable (Table 2) [13].

\section{DISCUSSION}

Lipoglycopeptide drug loss due to its binding to plastics is known to affect the MIC determination. The addition of P-80 to the MIC assay has resolved this issue and the FDA-approved rBMD method includes DMSO and $\mathrm{P}-80$ to improve drug solubility and reduce drug loss, respectively [8, 14-17]. Telavancin is a lipoglycopeptide active against a wide range of susceptible Gram-positive pathogens, including S. aureus [13]. The objective of this study was to 

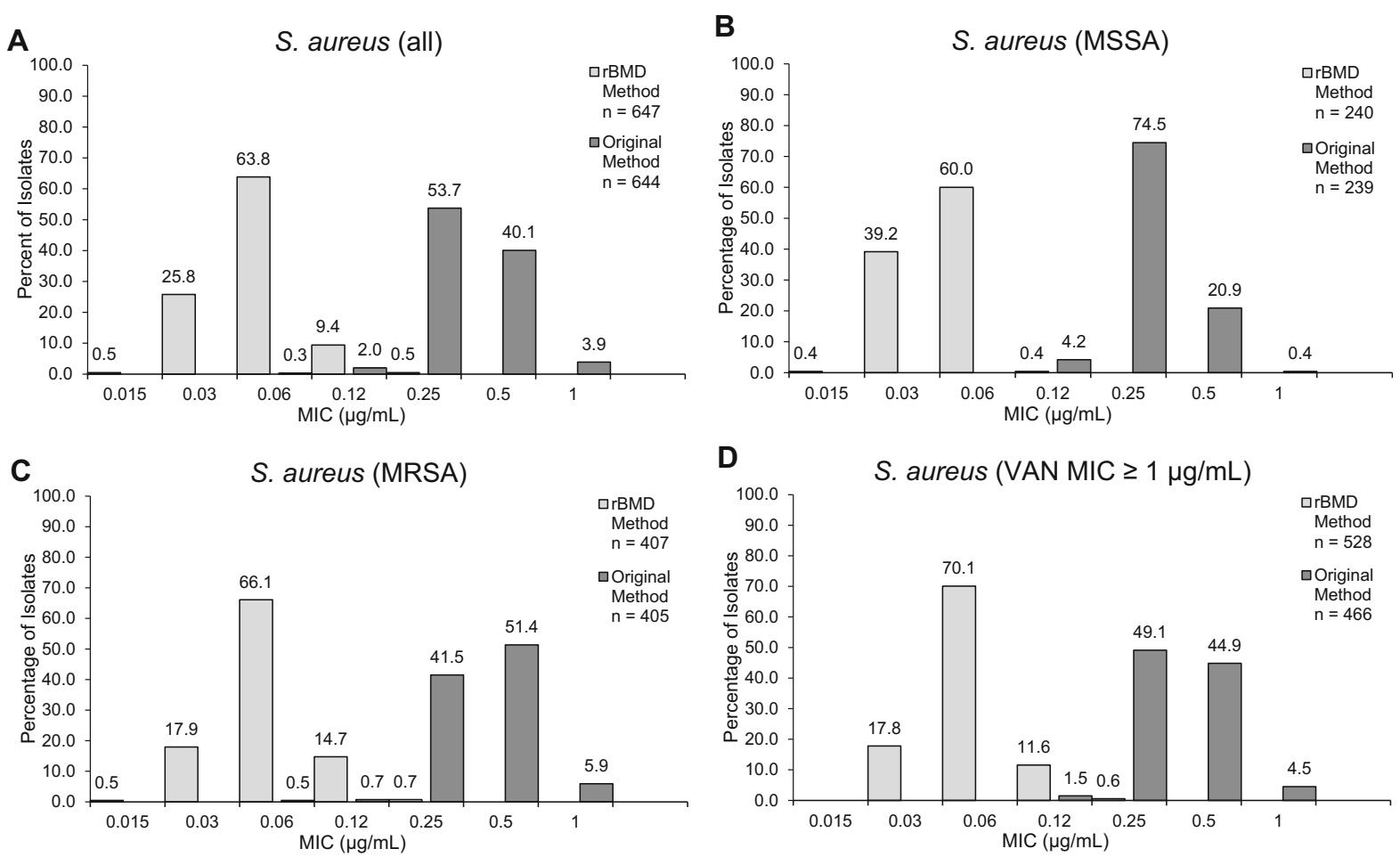

Fig. 1 Distribution of telavancin MICs obtained using the rBMD or original BMD method in a all $S$. aureus isolates, b MSSA isolates, c MRSA isolates, and $\mathbf{d} S$. aureus isolates with vancomycin $\mathrm{MICs} \geq 1 \mu \mathrm{g} / \mathrm{mL}$. MIC minimum

inhibitory concentration; $M R S A$ methicillin-resistant $S$. aureus; MSSA methicillin-susceptible $S$. aureus; $r B M D$ revised broth microdilution; $S$. aureus Staphylococcus aureus; $V A N$ vancomycin

re-evaluate the ATTAIN clinical isolates with the rBMD method that has previously demonstrated lower telavancin MIC values $[8,16,17]$.

Telavancin MIC values for MSSA and MRSA obtained using the rBMD method were lower than those that have been published elsewhere using the original method [21, 22], indicating that telavancin is more active in vitro against $S$. aureus isolates than previously considered. In this study, the rBMD method produced an overall 4-fold decrease in the telavancin $\mathrm{MIC}_{50 / 90}$ for $S$. aureus compared with the original method. All isolates were susceptible to telavancin, consistent with other studies reporting telavancin susceptibility of $S$. aureus using the rBMD method $[18,19]$. Telavancin

also retained its in vitro potency against isolates with reduced susceptibility to vancomycin (MIC $\geq 1 \mu \mathrm{g} / \mathrm{mL}$ ). Furthermore, the reassessment of ATTAIN study clinical isolates using the rBMD method demonstrated robust clinical cure and microbiological eradication even at the highest telavancin MIC $(0.12 \mu \mathrm{g} / \mathrm{mL})$ observed in the study.

This study is limited by its retrospective nature. The patients were not prospectively stratified by MIC and the reduced sample size prevented extensive statistical analyses of the clinical cure rates. However, the Clopper-Pearson (Exact) confidence interval method [22] was applied to demonstrate that the clinical cure rates were comparable across all $S$. aureus isolates and telavancin MICs. 


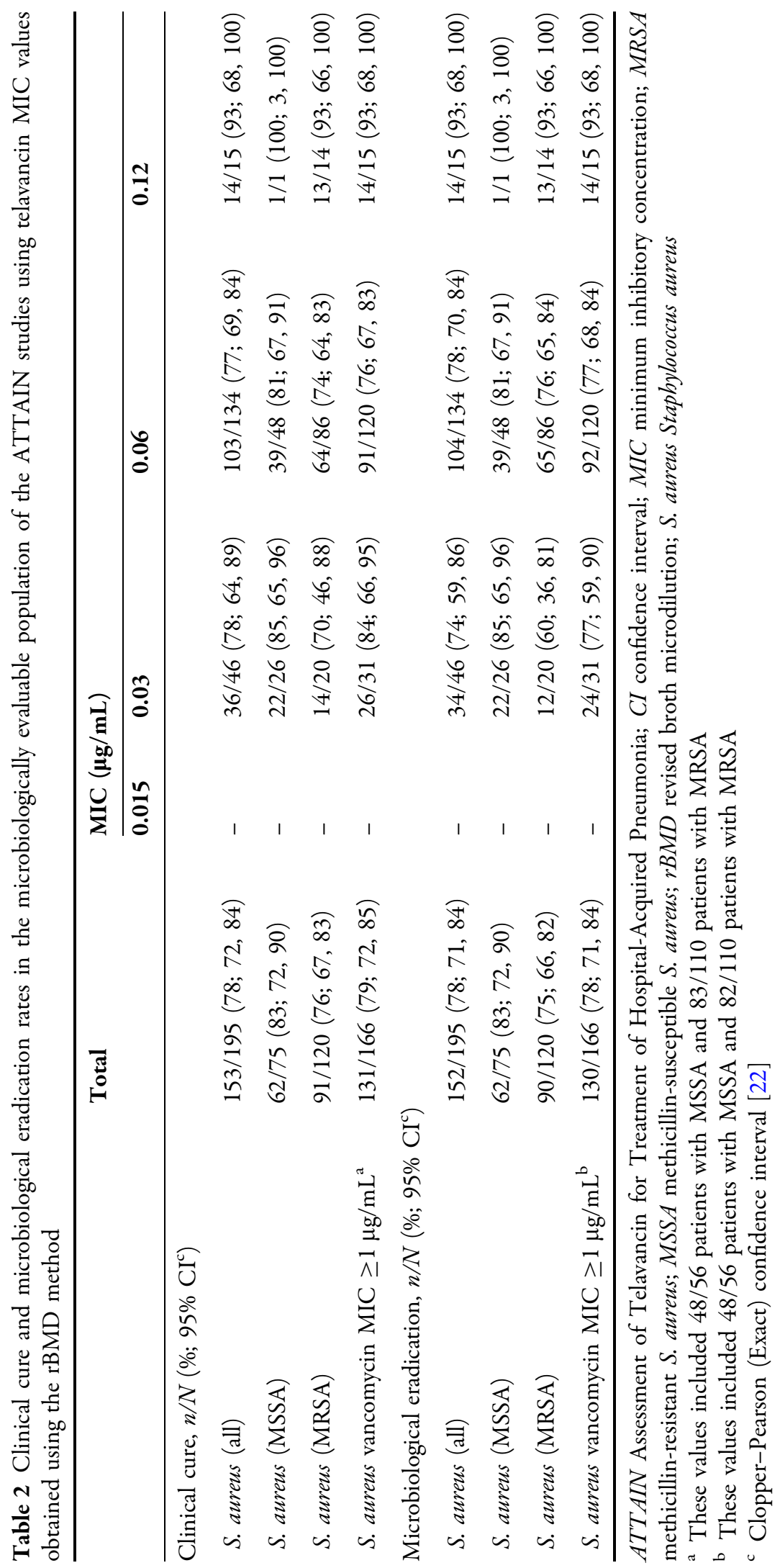




\section{CONCLUSION}

Reassessment of the ATTAIN isolates using the rBMD method demonstrated increased in vitro potency of telavancin against $S$. aureus. These data support lowering the telavancin susceptibility breakpoint to $0.12 \mu \mathrm{g} / \mathrm{mL}$ for $S$. aureus. Moreover, these results suggest that published studies using the previous BMD underestimated the in vitro potency of telavancin $[23,24]$.

\section{ACKNOWLEDGMENTS}

Sponsorship and article processing charges for this study were funded by Theravance Biopharma Antibiotics, Inc., George Town, Cayman Islands.

All named authors meet the International Committee of Medical Journal Editors (ICMJE) criteria for authorship for this manuscript, take responsibility for the integrity of the work as a whole, and have given final approval to the version to be published.

The authors wish to acknowledge the staff at JMI Laboratories for their efforts in coordinating the receipt of bacterial isolates from the ATTAIN clinical study sites as well as for conducting the MIC analyses. Editorial support in the form of manuscript writing (outline and first draft), styling, and submission was provided by Jill See, PhD, of AlphaBioCom, LLC (King of Prussia, PA, USA), and was funded by Theravance Biopharma Antibiotics, Inc.

Disclosures. J.I. Smart is an employee of Theravance Biopharma US, Inc. W. Wang is an employee of Theravance Biopharma US, Inc. S.L. Barriere is a former employee of Theravance Biopharma US, Inc., and received personal fees during the conduct of the study. G.R. Corey reports personal fees from Theravance during the conduct of the study. In addition, G.R. Corey reports personal fees from Nabriva, Medtronic, Pfizer, Cempra, Cerexa/Forest/ Actavis, Trius/Cubist/Merck, Achaogen, GlaxoSmithKline, Melinta, and Motif; and grants and personal fees from The Medicines Company and Dr. Reddy's Lab, outside the submitted work. M.E. Stryjewski reports grants from Theravance during the conduct of the study. In addition, Dr. Stryjewski reports personal fees from Cerexa and Achaogen; and grants from Duke Clinical Research Institute, The Medicines Company, JMI Laboratories, Theravance, and Cempra outside the submitted work.

Compliance with Ethics Guidelines. This article is based on previously conducted studies, and does not involve any new studies of human or animal subjects performed by any of the authors.

Open Access. This article is distributed under the terms of the Creative Commons Attribution-NonCommercial 4.0 International License (http://creativecommons.org/licenses/ by-nc/4.0/), which permits any noncommercial use, distribution, and reproduction in any medium, provided you give appropriate credit to the original author(s) and the source, provide a link to the Creative Commons license, and indicate if changes were made.

\section{REFERENCES}

1. Tong SY, Davis JS, Eichenberger E, Holland TL, Fowler VG Jr. Staphylococcus aureus infections: epidemiology, pathophysiology, clinical manifestations, and management. Clin Microbiol Rev. 2015;28(3):603-61. 
2. Kalil AC, Metersky ML, Klompas M, Muscedere J, Sweeney DA, Palmer LB, et al. Management of adults with hospital-acquired and ventilator-associated pneumonia: 2016 clinical practice guidelines by the Infectious Diseases Society of America and the American Thoracic Society. Clin Infect Dis. 2016;63(5):e61-111.

3. Lodise TP, Graves J, Evans A, Graffunder E, Helmecke M, Lomaestro BM, et al. Relationship between vancomycin MIC and failure among patients with methicillin-resistant Staphylococcus aureus bacteremia treated with vancomycin. Antimicrob Agents Chemother. 2008;52(9):3315-20.

4. Wang JL, Lai CH, Lin HH, Chen WF, Shih YC, Hung $\mathrm{CH}$. High vancomycin minimum inhibitory concentrations with heteroresistant vancomycin-intermediate Staphylococcus aureus in methicillin-resistant $S$. aureus bacteraemia patients. Int J Antimicrob Agents. 2013;42(5):390-4.

5. Jacob JT, DiazGranados CA. High vancomycin minimum inhibitory concentration and clinical outcomes in adults with methicillin-resistant Staphylococcus aureus infections: a meta-analysis. Int J Infect Dis. 2013;17(2):e93-100.

6. Soriano A, Marco F, Martinez JA, Pisos E, Almela M, Dimova VP, et al. Influence of vancomycin minimum inhibitory concentration on the treatment of methicillin-resistant Staphylococcus aureus bacteremia. Clin Infect Dis. 2008;46(2):193-200.

7. Higgins DL, Chang R, Debabov DV, Leung J, Wu T, Krause KM, et al. Telavancin, a multifunctional lipoglycopeptide, disrupts both cell wall synthesis and cell membrane integrity in methicillin-resistant Staphylococcus aureus. Antimicrob Agents Chemother. 2005;49(3):1127-34.

8. VIBATIV $^{\circledR}$ (telavancin), USP [package insert]. South San Francisco: Theravance Biopharma US, Inc; 2016.

9. Lunde CS, Hartouni SR, Janc JW, Mammen M, Humphrey PP, Benton BM. Telavancin disrupts the functional integrity of the bacterial membrane through targeted interaction with the cell wall precursor lipid II. Antimicrob Agents Chemother. 2009;53(8):3375-83.

10. Karlowsky JA, Nichol K, Zhanel GG. Telavancin: mechanisms of action, in vitro activity, and mechanisms of resistance. Clin Infect Dis. 2015;61(Suppl 2):S58-68.

11. Summary of Product Characteristics (VIBATIV $250 \mathrm{mg}$ powder for concentrate for solution for infusion) Bridgend, United Kingdom: Biotec
Services International Limited; 2011. http:// www.ema.europa.eu/docs/en_GB/document_library/ EPAR_-_Product_Information/human/001240/WC50 0115364.pdf. Accessed Jan 4, 2016.

12. Theravance Biopharma Announces Marketing Authorization for $\operatorname{VIBATIV}(\mathrm{R})$ (Telavancin) in Russia for Treatment of Multiple Infections Caused by Gram-Positive Bacteria, Including MRSA Dublin, Ireland: Theravance Biopharma; 2015. http://investor.theravance.com/releasedetail. cfm?releaseid=920028. Accessed Jan 4, 2016.

13. Rubinstein E, Lalani T, Corey GR, Kanafani ZA, Nannini EC, Rocha MG, et al. Telavancin versus vancomycin for hospital-acquired pneumonia due to gram-positive pathogens. Clin Infect Dis. 2011;52(1):31-40.

14. Arhin FF, Sarmiento I, Belley A, McKay GA, Draghi DC, Grover P, et al. Effect of polysorbate 80 on oritavancin binding to plastic surfaces: implications for susceptibility testing. Antimicrob Agents Chemother. 2008;52(5):1597-603.

15. Fritsche TR, Rennie RP, Goldstein BP, Jones RN. Comparison of dalbavancin MIC values determined by Etest (AB BIODISK) and reference dilution methods using gram-positive organisms. J Clin Microbiol. 2006;44(8):2988-90.

16. CLSI. Performance standards for antimicrobial susceptibility testing; twenty-fourth international supplement. Wayne, PA: Clinical Laboratory and Standards Institute; 2014.

17. Farrell DJ, Mendes RE, Rhomberg PR, Jones RN. Revised reference broth microdilution method for testing telavancin: effect on MIC results and correlation with other testing methodologies. Antimicrob Agents Chemother. 2014;58(9):5547-51.

18. Mendes RE, Farrell DJ, Sader HS, Streit JM, Jones RN. Update of the telavancin activity in vitro tested against a worldwide collection of Gram-positive clinical isolates (2013), when applying the revised susceptibility testing method. Diagn Microbiol Infect Dis. 2015;81(4):275-9.

19. Mendes RE, Flamm RK, Farrell DJ, Sader HS, Jones RN. Telavancin activity tested against Gram-positive clinical isolates from European, Russian and Israeli hospitals (2011-2013) using a revised broth microdilution testing method: redefining the baseline activity of telavancin. J Chemother; 2015:1973947815Y0000000050.

20. CLSI. Performance Standards for Antimicrobial Susceptibility Testing. 26th ed. CLSI supplement M100S. Clinical and Laboratory Standards Institute; 2016. 
21. Mendes RE, Sader HS, Farrell DJ, Jones RN. Worldwide appraisal and update (2010) of telavancin activity tested against a collection of Gram-positive clinical pathogens from five continents. Antimicrob Agents Chemother. 2012;56(7):3999-4004.

22. Newcombe RG. Two-sided confidence intervals for the single proportion: comparison of seven methods. Stat Med. 1998;17(8):857-72.

23. Pfaller MA, Mendes RE, Sader HS, Jones RN. Telavancin activity against Gram-positive bacteria isolated from respiratory tract specimens of patients with nosocomial pneumonia. J Antimicrob Chemother. 2010;65(11):2396-404.

24. Saravolatz LD, Pawlak J, Johnson LB. Comparative activity of telavancin against isolates of community-associated methicillin-resistant Staphylococcus aureus. J Antimicrob Chemother. 2007;60(2):406-9. 